\title{
LA PROTECCIÓN DEL MEDIO AMBIENTE COMO NORMA IMPERATIVA DE DERECHO INTERNACIONAL (IUS COGENS)
}

\author{
THE PROTECTION OF THE ENVIRONMENT AS AN \\ IMPERATIVE NORM OF INTERNATIONAL LAW \\ (IUS COGENS)
}

\section{A PROTEÇÃO DO MEIO AMBIENTE COMO NORMA IMPERATIVA DE DIREITO INTERNACIONAL (IUS COGENS)}

\author{
PEDRO LORENZO*
}

\begin{abstract}
RESUMEN: El autor se plantea la hipótesis de si las normas de protección del medio ambiente configuran a la fecha una norma imperativa de derecho internacional (Ius Cogens). Para comprobar su hipótesis, contrarresta el estado actual del Derecho, con los últimos avances en los estudios sobre Ius Cogens de la Comisión de Derecho Internacional (CDI) de las Naciones Unidas.
\end{abstract}

El objetivo primario del trabajo es contribuir desde la academia a los esfuerzos que está realizando la CDI en el estudio de Ius Cogens. El autor entiende necesario que la República Oriental del Uruguay esté formalmente presente en la discusión sobre la temática de Ius Cogens en general y particularmente en el aporte al estado actual de Derecho Internacional del Medio Ambiente.

El presente trabajo es la culminación de la investigación realizada para la aprobación del XLVI Curso de Derecho Internacional de la Organización de Estados Americanos, dictado en Rio de Janeiro, Brasil en julio - agosto 2019.

PALABRAS CLAVE: Ius Cogens, Normas imperativas, Derecho Internacional, Medio Ambiente, Derecho Ambiental.

ABSTRACT: The author hypothesizes whether environmental protection norms, to date, constitute an imperative norm of international law (Ius Cogens). To test his hypo-

\footnotetext{
* Abogado y Licenciado en Relaciones Internacionales por la Universidad de la República, Uruguay. Actualmente se desempeña como Profesional de Comercio Exterior en ANCAP y es Aspirante a Profesor Adscripto de Derecho Internacional Público en UDELAR. ORCID: https: / / orcid.org/0000-0003-2234-5862. pedrolorenzoarana@gmail.com
} 
thesis, he counteracts the current state of law, with the latest advances in the studies on Ius Cogens of the International Law Commission (ILC) of the United Nations.

The primary objective of the article is to contribute, from the academy, to the efforts that the ILC is making in the study of Ius Cogens. The author considers necessary that Uruguay be formally present in the discussion on the subject of Ius Cogens in general and particularly in the contribution to the current state of International Environmental Law.

This work is the culmination of the research carried out for the approval of the XLVI Course on International Law of the Organization of American States, held in Rio de Janeiro, Brazil in July - August 2019.

KEY WORDS: Ius Cogens, Imperative norms, International law, Environment, Environment law.

RESUMO: $\mathrm{O}$ autor se propõe a hipótese de se as normas de proteção do meio ambiente configuram, atualmente, uma norma imperativa do direito internacional (Ius Cogens). Para comprovar sua hipótese, ele contraria o estado atual do Direito, com os últimos avanços nos estudos sobre Ius Cogens da Comissão de Direito Internacional (CDI) das Nações Unidas.

O objetivo primário do trabalho é contribuir, a partir da academia, para os esforços que a CDI está fazendo no estudo do Ius Cogens. O autor considera necessário que a República Oriental do Uruguai esteja formalmente presente na discussão sobre o tema Ius Cogens, em geral e particularmente na contribuição para o atual estado do Direito Internacional do Meio Ambiente.

O presente trabalho é a culminação da pesquisa feita para a aprovação do XLVI Curso de Direito Internacional da Organização dos Estados Americanos, realizado no Rio de Janeiro, Brasil em julho - agosto 2019.

PALAVRAS-CHAVE: Ius Cogens, Normas imperativas, Direito Internacional, Meio Ambiente, Direito Ambiental.

\section{INTRODUCCIÓN.}

La Comisión de Derecho Internacional de las Naciones Unidas ha realizado una lista no taxativa de normas imperativas de derecho internacional entre las cuales no se encuentra la protección del medio ambiente ${ }^{1}$.

En el cuarto informe del relator especial Dr. Dire Tladi sobre normas imperativas de derecho internacional general (ius cogens), se expresa que existen ciertas normas que

\footnotetext{
1 Comisión de Derecho Internacional 71er período de sesiones. Ginebra, 29 de abril a 7 de junio y 8 de julio a 9 de agosto de 2019. Fecha 24 de mayo de 2019. Texto del proyecto de conclusiones por el Comité de Redacción en primera lectura. Documento A/CN.4/L.936 disponible en https:/ / undocs.org/es/A/CN.4/L.936. En el texto de proyecto de conclusiones y del proyecto de anexo aprobados provisionalmente por el Comité de Redacción de la Comisión de Derecho Internacional, en primera lectura, figuran las siguientes normas como imperativas de derecho internacional general (ius cogens): La prohibición de la agresión; La prohibición del genocidio; La prohibición de los crímenes de lesa humanidad; Las normas básicas del derecho internacional humanitario; La prohibición de la discriminación racial y el apartheid; La prohibición de la esclavitud; La prohibición de la tortura; El derecho a la libre determinación.
} 
podrían tener carácter de ius cogens, y cuya inderogabilidad podría lograr el reconocimiento y la aceptación necesarios en el futuro, como lo es el deber de proteger el medio ambiente (o algunos aspectos de este deber) ${ }^{2}$.

La Comisión de Derecho Internacional ha decidido, en cumplimiento de los artículos 16 a 21 de su estatuto, transmitir el borrador de conclusiones, a través de la Secretaría General de las Naciones Unidas a los gobiernos para que realicen comentarios y observaciones, con la solicitud de que dichos comentarios y observaciones sean enviados al Secretario General antes del 01 de diciembre del año $2020^{3}$.

El objetivo general primario del presente trabajo será contribuir a que el Instituto de Derecho Internacional Público de la Universidad de la República de Montevideo, Uruguay, y las demás Universidades de nuestro país, comiencen un estudio sobre la temática de ius cogens a los efectos de hacer llegar al Ministerio de Relaciones Exteriores de la República Oriental del Uruguay su punto de vista al respecto y de esta manera alentar una respuesta del Estado uruguayo ante tan importante consulta ${ }^{4}$. Se intentará contribuir en la búsqueda de pruebas sobre la imperatividad de las normas que protegen el medio ambiente, como insumo a la discusión.

El objetivo general secundario del trabajo será contribuir en la difusión de la labor de la Comisión de Derecho Internacional de las Naciones Unidas en los países miembros de la Organización de Estados Americanos y especialmente en la labor del Comité Jurídico Interamericano.

Hipótesis: Las normas que tienen por objeto la protección del medio ambiente son normas imperativas de Derecho Internacional (Ius Cogens).

\section{LAS NORMAS IMPERATIVAS DE DERECHO INTERNACIONAL (IUS COGENS).}

El Relator Especial de la Comisión de Derecho Internacional de las Naciones Unidas sobre las normas imperativas de derecho internacional general (ius cogens), Profesor Dire Tladi realiza una descripción de las normas de derecho internacional estableciendo una bifurcación ${ }^{5}$ :

\footnotetext{
2 Comisión de Derecho Internacional 71er período de sesiones. Ginebra, 29 de abril a 7 de junio y 8 de julio a 9 de agosto de 2019. Fecha 31 de enero de 2019 Cuarto informe sobre las normas imperativas de derecho internacional general (ius cogens) presentado por Dire Tladi, Relator Especial. Documento A/CN.4/727 disponible en https://undocs.org/es/A/ CN.4/727

3 http://legal.un.org/ilc/sessions/71/

4 Posteriormente a cada sesión anual de la Comisión de Derecho Internacional de las Naciones Unidas, donde se analizaron los cuatro informes realizados por el Relator Especial, se solicitó a los Gobiernos que enviaran sus comentarios respecto a cada uno de los informes y proyectos de artículos. Posterior a la sesión número 68, en el año 2016 se recibieron cinco comentarios (Austria, Alemania, Países Bajos, Paraguay y España); Posterior a la sesión número 69, en el año 2017 se recibieron dos comentarios (Austria y México); Posterior a la sesión número 70, en el año 2018 se recibió un comentario (Austria). Fuente: sitio WEB de la Comisión de Derecho Internacional: https://legal.un.org/ilc/guide/1_14.shtml

5 La Dra. Aldana Rohr nos ilustra que "La mayor parte de la doctrina concuerda en que una de las características del derecho internacional público es que se compone de dos tipos de normas de jerarquía diferente en razón a su poder derogatorio: por un lado, aquellas de naturaleza dispositiva — jus dispositivum -, las más numerosas, creadas por acuerdo de voluntades, derogables también por acuerdos de voluntades y generadas sobre un sistema de coordinación y, por otro lado, las normas de derecho perentorio o im-
} 
A) Ius dispositivum: son la mayoría de las normas de derecho internacional. Los sujetos de derecho internacional tienen la más amplia potestad normativa (formación, vigencia y derogación).

B) Ius cogens: son normas imperativas de derecho internacional general. En la actualidad existen normas jurídicas internacionales que han sido reconocidas por los Estados como normas imperativas, de acuerdo a lo establecido en el artículo 53 de la Convención de Viena sobre Derecho de los Tratados.

En virtud de un enfoque compartible, el Profesor Tladi intenta no ingresar en la discusión filosófica sobre las distintas concepciones del origen de las normas jurídicas (positivismo jurídico o iusnaturalismo) ya que implicaría necesariamente tomar partido por alguna de las corrientes. Lo que busca el Relator Especial en la serie de extensos informes, ha sido realizar una descripción actual sobre el estado de avance científico en el estudio de las normas imperativas de derecho internacional general.

El artículo 53 de la Convención de Viena sobre Derecho de los Tratados establece que "Es nulo todo tratado que, en el momento de su celebración, esté en oposición con una norma imperativa de derecho internacional general. Para los efectos de la presente Convención, una norma imperativa de derecho internacional general es una norma aceptada y reconocida por la comunidad internacional de Estados en su conjunto como norma que no admite acuerdo en contrario y que solo puede ser modificada por una norma ulterior de derecho internacional general que tenga el mismo carácter".

A partir de este texto normativo, que fue ampliamente discutido dentro de la Comisión de Derecho Internacional y en la Conferencia de Viena, surge con meridiana claridad que las normas ius cogens son aceptadas y reconocidas por los Estados. Es interesante recordar el momento histórico en el cual se firmó la Convención de Viena, en medio de las tensas relaciones entre las potencias hegemónicas de la época, Estados Unidos y la Unión Soviética ${ }^{6}$.

Aldana ROHR nos enseña que "La principal característica distintiva entre estas normas es el carácter inderogable de las normas de jus cogens. Son normas de derecho consuetudinario que no pueden dejarse de lado por tratados o por aquiescencia, sino sólo por la formación de una norma consuetudinaria posterior, de efecto contrario y del mismo nivel", posteriormente, ROHR incorpora la opinión de DIEZ DE VELASCO destacando que "las normas dispositivas pretenden satisfacer los intereses individuales, las imperativas en cambio, pretenden dar respuesta a los intereses colectivos esenciales de todo el grupo social, que son propios de la nueva estructura

perativo — jus cogens - , pertenecientes a un sistema que podría entenderse como de cuasisubordinación normativa, que limita, en cierta manera, la voluntad estatal derivada de su propia soberanía. Estas pocas normas representan, en palabras de Carrillo Salcedo, el "mínimo jurídico esencial que la comunidad internacional precisa para supervivir". En: "La responsabilidad internacional del Estado por violación al Jus Cogens", página 5.

6 Akehurst, Michael “A Modern Introduction to International Law”. Séptima edición página 57. Desde la primer edición (1970) el autor afirma que "el estado más a favor de esta regla es la Unión Soviética". 
comunitaria y que exigen reglas cualificadas por su grado de obligatoriedad, lo que conlleva la superior jerarquía de las mismas frente al resto de normas del ordenamiento"7.

Nuestro Profesor, Dr. Roberto PUCEIRO ${ }^{8}$, enumera, además del carácter inderogable, otras características de las normas ius cogens, como ser: "imperatividad, generalidad, aceptación y reconocimiento universal, dinamismo y mutabilidad". Es muy interesante la característica de la mutabilidad, sobre la cual el Dr. PUCEIRO nos ilustra diciendo que "Las normas de jus cogens no son inmutables y pueden ser derogadas o modificadas por otras del mismo carácter que surjan posteriormente. Por su objeto y naturaleza, son variables y evolutivas, adaptándose a las concepciones que las originan, a las necesidades que atienden y a los fines que cumplen".

En los últimos cincuenta años, el desarrollo progresivo del Derecho Internacional ha sido exponencial. La regulación del derecho de los tratados significó que hubiera una armonización en la interpretación y formación de tratados, lo que sin lugar a dudas, implicó un gran avance en la seguridad jurídica de la comunidad internacional. El "ius dispositivum" afloró de gran forma regulando multiplicidad de temáticas a nivel internacional. Sin embargo, no ocurrió lo mismo con las normas imperativas de derecho internacional general. Éstas últimas han tenido un desarrollo mucho menos vigoroso. Los Estados se han mostrado reacios a expresarse con firmeza para catalogar a una norma de derecho internacional general como ius cogens.

Existen múltiples razones por las cuales los estados han limitado sus expresiones favorables acerca de declarar una norma como ius cogens. La principal obviamente es que, una vez aceptada por la "comunidad internacional de Estados en su conjunto" un Estado individualmente considerado, pierde potestad de disposición normativa y quedará sujeto a una norma que es inderogable (sólo podría ser modificada por otra norma imperativa de derecho internacional general).

La Comisión de Derecho Internacional ha sido muy diligente en volver a poner el tema del ius cogens en la discusión pública internacional. La escalada de conflictos internacionales, las graves violaciones a los derechos humanos y la degradación ambiental sin precedentes, necesariamente implican un esfuerzo de la comunidad internacional de juristas, con el objetivo de contribuir en la búsqueda de herramientas jurídicas en la cuales sustentar las soluciones que nuestro planeta necesita.

\section{REQUISITOS PARA QUE UNA NORMA SEA CONSIDERADA COMO NORMA IMPERATIVA DE DERECHO INTERNACIONAL (IUS COGENS).}

El Relator Especial nos ilustra que "la definición de la Convención de Viena se acepta como definición de ius cogens, en términos generales, incluso más allá del derecho de los tratados"9.

7 En: La responsabilidad internacional del Estado por violación al jus cogens / Aldana Rohr. - 1a ed . - Avellaneda : SGN Editora, 2015. Página 7 (cita a Juan Antonio TRAVIESO).

8 Puceiro Ripoll, Roberto. "Las normas de Jus Cogens en el campo del derecho internacional contemporáneo". En "Derecho Internacional Público" Tomo 1, Jiménez de Aréchaga, Arbuet-Vignali y Puceiro Ripoll. Fundación de Cultura Universitaria. Primera edición, noviembre 2005. Páginas 368 a 374.

9 A/CN.4/706 Segundo informe sobre ius cogens presentado por Dire Tladi, Relator Especial. 16 de marzo de 2017. 
Posteriormente nos indica que el citado artículo 53 establece dos criterios acumulativos para la determinación de las normas ius cogens.

1. La norma en cuestión debe ser una norma de derecho internacional general.

2. Debe estar aceptado y reconocido que esa norma de derecho internacional general es una norma que no admite acuerdo en contrario.

Existen otras teorías que incluyen como criterio también el hecho de que una norma ius cogens solo puede ser modificada por una norma ulterior del mismo carácter. Entendemos que esta característica no se establecería como un criterio para describir una norma ius cogens sino un criterio normativo de cómo, una vez aceptada la imperatividad de una norma, ésta se podría eventualmente modificar.

El primer criterio definitorio sería que la norma debe ser de "derecho internacional general". El Relator Especial establece que "el adjetivo "general" en la expresión "normas de derecho internacional general" se refiere al alcance de la aplicabilidad". GONZÁLEZ NAPOLITANO señala que "las normas generales son aquellas que vinculan a toda o a casi toda la comunidad internacional, independientemente de si los sujetos obligados participaron o no en el proceso de elaboración" 10 .

No sería correcto interpretar el adjetivo "general" en contraposición a una "ley especial" ya que dicha interpretación implicaría que muchas normas internacionales consideradas "normas especiales" no pudieran llegar a ser normas ius cogens. Esta distinción es importante para materias como el derecho internacional humanitario, o, por ejemplo, las normas que protegen el medio ambiente, que bien pueden considerarse normas especiales y sobre las cuales estudiaremos más adelante su posible consideración como normas imperativas de derecho internacional general - ius cogens. "Los principios generales de derecho, al igual que las normas de derecho internacional consuetudinario, son de aplicación general"11.

El Relator Especial concluye que tanto los principios generales de derecho ${ }^{12}$ y el derecho internacional consuetudinario son fuentes de normas ius cogens. ${ }^{13}$ Posteriormen-

\footnotetext{
Punto 36 página 16.

10 González Napolitano, Silvina S., "Fuentes y normas del derecho internacional”, en Lecciones de Derecho Internacional Público, González Napolitano, Silvina S. (coord.), Errepar, Buenos Aires, 2015, página 82-83.

11 A/CN.4/706 Segundo informe sobre ius cogens presentado por Dire Tladi, Relator Especial. 16 de marzo de 2017. Punto 36 página 23.

La Corte Interamericana de Derechos Humanos en la opinión consultiva OC 23-17, sobre Medio Ambiente y Derechos Humanos se expresa estableciendo que "Las cuestiones planteadas en la solicitud trascienden el interés de los Estados parte del Convenio de Cartagena y son de importancia para todos los Estados del planeta." Párrafo 35, página 17.

12 Con relación a los principios generales de derecho como fuente del derecho internacional público, Leopoldo GODIO concluye que "Se trata de una fuente flexible y conveniente de gran utilidad que, en extremo, pueden constituir mecanismos para un desarrollo progresivo del derecho internacional aplicable, por ejemplo, al derecho internacional de los derechos humanos, el derecho internacional ambiental y el comercio internacional, entre otros". En: "Los principios generales de derecho como fuente del derecho internacional público" Revista de derecho de la Universidad de Montevideo, número 30 - año 2016 página 65.

13 A/CN.4/706 Segundo informe sobre ius cogens presentado por Dire Tladi, Relator Especial. 16 de marzo de 2017. Punto 36 página 25. En este respecto, es menester traer a colación la posición de Uruguay en la discusión dada en el seno de la Conferencia de Viena, donde expresamente se pronunció a favor de que algunos principios generales del derecho pudieran alcanzar el rango de ius cogens.
} 
te, nos indica que "si bien las disposiciones de los tratados no constituyen, en sí, normas de derecho internacional general capaces de ser fuente de normas de ius cogens, pueden reflejar normas de derecho internacional general que pueden alcanzar el rango de ius cogens". Esta conclusión será importante a la hora de estudiar las normas internacionales de protección del medio ambiente, ya que, en su mayoría, se han expresado como normas convencionales multilaterales.

\section{CONSECUENCIAS DE CONSIDERAR UNA NORMA COMO NOR- MA IMPERATIVA DE DERECHO INTERNACIONAL (IUS COGENS).}

La Comisión de Derecho Internacional ha enumerado consecuencias para diversas situaciones jurídicas que se ven afectadas por una norma imperativa de derecho internacional (ius cogens). Enumeraremos alguna de dichas consecuencias que consideramos más importantes a la hora de centrarnos en nuestro objeto de estudio.

En la esfera del derecho de los tratados, la primera consecuencia que trae aparejada una norma imperativa de derecho internacional general, es la nulidad de los tratados cuyas normas contravienen el ius cogens. "La nulidad es una consecuencia de gran alcance, porque afecta el corazón de un elemento básico y fundamental del derecho internacional, a saber, el principio pacta sunt servanda. Restringe significativamente la autoridad de los Estados en materia de elaboración de tratados, o incluso leyes". ${ }^{14}$ Si bien la Convención de Viena sobre derecho de los tratados establece la posibilidad de divisibilidad o abstracción de las disposiciones de un tratado que se declaren nulas, esta disposición no aplica para nulidades que provengan de contravenciones al ius cogens. Dicho de otra forma, las disposiciones de un tratado nulas por incompatibilidad con el ius cogens no pueden separarse del tratado.

En la situación jurídica de que, a posteriori de la vigencia de un tratado, surja una nueva norma ius cogens que sea incompatible con el tratado anterior en el tiempo, éste terminará en su totalidad, a menos que, las disposiciones incompatibles, no constituyan la base esencial del consentimiento en el tratado, que además, dichas obligaciones sean separables en su totalidad en lo que respecta a su aplicación, y que no convierta la aplicación del tratado en una injusticia. ${ }^{15}$

En lo que respecta a la interpretación de los tratados, "un intérprete debe, en la medida de lo posible, interpretar un tratado de manera que no entre en conflicto con una norma de ius cogens" 16 .

\footnotetext{
Con una posición interpretativa distinta, SHAW considera que "está claro que sólo las reglas que se basan en la costumbre o los tratados pueden formar la base de normas de jus cogens, teniendo en consideración la actitud hostil de muchos Estados a aceptar los principios generales como fuente independiente de derecho internacional y la exigencia de la universalidad de la formación de las normas jus cogens" Citado por Rohr: "La responsabilidad internacional del Estado por violación al jus cogens / Aldana Rohr. - 1a ed . - Avellaneda : SGN Editora, 2015. Página 18.

14 A/CN4.714 Tercer informe sobre las normas imperativas de derecho internacional general (ius cogens) presentado por Dire Tladi, Relator Especial. Página 15.

15 A/CN4.714 páginas 18 a 20.

16 A/CN4.714 página 26.
} 
En relación a los derechos y deberes de los Estados, existe un deber de no reconocer como lícita una situación creada por una violación de una norma imperativa de derecho internacional general y una obligación de abstenerse a prestar ayuda o asistencia para mantener una situación creada por una violación a una norma ius cogens ${ }^{17}$.

Las normas imperativas de derecho internacional general (ius cogens) establecen obligaciones erga omnes cuyo incumplimiento concierne a todos los Estados ${ }^{18}$.

Existe una discusión teórica sobre la relación entre las normas ius cogens y las llamadas obligaciones erga omnes ${ }^{19}$. Compartimos plenamente la deducción lógica que propone el Relator Especial Dire Tladi cuando afirma que "los dos conceptos no son iguales, uno emana (obligación erga omnes) del otro" (norma imperativa de derecho internacional general -ius cogens-). Los comentarios entre paréntesis nos pertenecen.

Como cualquier obligación, las obligaciones erga omnes también requieren un sustento normativo - o en otra palabra- derecho. Dicho sustento deberá estar a la altura, en el caso de las obligaciones erga omnes, de que sus supuestos creen situaciones jurídicas que impliquen un "deber ser" y que motiven el comportamiento de los sujetos de derecho internacional. Si bien la discusión teórica puede parecer trivial, es importante traerla a colación en el presente trabajo por lo que se verá más adelante.

El Relator Especial enumera otras consecuencias jurídicas de considerar una norma como ius cogens. Si bien son conclusiones excelentes, no son pertinentes para el objeto de estudio del presente trabajo, por lo que remitiremos a su lectura. ${ }^{20}$

\section{ENUNCIACIÓN DE LAS PRINCIPALES NORMAS INTERNA- CIONALES DE PROTECCIÓN DEL MEDIO AMBIENTE.}

No es adecuado para el alcance del presente trabajo realizar una lista exhaustiva de todas las normas internacionales de protección del medio ambiente. De acuerdo a lo establecido en el artículo 38 del Estatuto de la Corte Internacional de Justicia (en

$\begin{array}{ll}17 & \text { A/CN4.714 página } 43 . \\ 18 & \text { A/CN4.714 página } 46 .\end{array}$

19 El Profesor Tladi resume parte de la discusión en los siguientes términos, cuyos fragmentos entendemos vale reproducir: "La causa relativa a la Barcelona Traction fue, tal vez, el hito más importante en lo que respecta a la aparición de las obligaciones erga omnes y su relación con las normas ius cogens. En dicha causa, la Corte estableció una distinción entre las obligaciones contraídas por un Estado "respecto de otro Estado" y "las obligaciones de un Estado para con la comunidad internacional en su conjunto"... Es un hecho generalmente aceptado en la doctrina que, aunque todas las normas de ius cogens tienen efectos erga omnes, no puede afirmarse lo contrario, es decir, no todas las obligaciones erga omnes constituyen normas de ius cogens. Si bien esta idea está muy asentada, su rigor es, cuanto menos, dudoso. Plantea la cuestión de si existen obligaciones erga omnes que no se deriven de normas ius cogens.". A/CN4.714 páginas 43 a 45.

Por su parte, la Dra. Aldana Rohr, explica que "podemos reafirmar que no todas las obligaciones erga omnes son reaseguradas por normas imperativas de derecho internacional general, tal sería el caso del artículo 1 del Tratado sobre los principios que deben regir las actividades de los Estados en la exploración y la utilización del espacio ultraterrestre, incluso la Luna y otros cuerpos celestes o el artículo 136 de la Convención de Montego Bay sobre el Derecho del Mar". En: La responsabilidad internacional del Estado por violación al jus cogens / Aldana Rohr. - 1a ed . - Avellaneda : SGN Editora, 2015. Página 9.

20 Entre las consecuencias más interesantes: efecto de las normas ius cogens en la responsabilidad penal individual en el derecho penal internacional, en el ejercicio de la jurisdicción estatal, en la inmunidad de jurisdicción, en la competencia de la Corte Internacional de Justicia, en los actos unilaterales de los Estados o Resoluciones de organizaciones internacionales, incluidas las del Consejo de Seguridad. 
adelante CIJ), las fuentes de normas de derecho internacional son tres: las " $a$. convenciones internacionales, sean generales o particulares, que establecen reglas expresamente reconocidas por los estados litigantes; $b$. la costumbre internacional como prueba de una práctica generalmente aceptada como derecho; c. los principios generales de derecho reconocidos por las naciones civilizadas".

Entendemos más importante, enumerar una serie de principios de derecho internacional ambiental, ampliamente reconocidos por los Estados en distintos instrumentos jurídicos. Se han reconocido en instrumentos de tipo "soft law" (comúnmente bajo declaraciones internacionales al finalizar conferencias internacionales sobre distintas temáticas ambientales) y también en múltiples tratados bilaterales y multilaterales. El aporte de la comunidad internacional de estados en la descripción y jerarquización de estos principios ha sido muy importante.

En la descripción del Derecho Ambiental que realizaba MANTERO en 1995, establecía que es un derecho fundamentalmente preventivo, y sólo en menor grado represivo o indemnizatorio. "Esto es consecuencia de que la eliminación del daño causado al ambiente no siempre es posible, ni el daño es siempre reparable. El carácter preventivo se manifiesta no solo en que el derecho debe orientarse a que no se produzca el daño, sino también a que la acción humana sobre el derecho ambiental no debe orientarse en consecuencia a la simple conservación del medio, sino también a su modificación favorable"21.

En el momento de su emisión, las Declaraciones de Estocolmo y de Rio de Janeiro eran consideradas "Soft law". Hoy en día, existen juristas que entienden que los principales principios enumerados en dichas declaraciones tienen rango de normas jurídicas de carácter obligatorio para los estados, siendo aceptadas como normas jurídicas internacionales cuya fuente es la costumbre internacional. El reconocimiento declarativo de dichos principios, la concepción de que son obligatorios y la práctica de los estados han hecho que, en el estadio actual, puedan ser considerados normas consuetudinarias.

En base a la investigación realizada, se explicitarán algunos de los principales principios de derecho ambiental ${ }^{22}$ :

21 MANTERO SAN VICENTE, Osvaldo. Derecho Ambiental. Página 19. $1^{\text {a }}$ edición, setiembre 1995.

22 CAN ADO TRINDADE nos enseña que "Todo sistema jurídico tiene principios fundamentales, que inspiran, informan y conforman sus normas. Son los principios (derivados etimológicamente del latín principum) que, evocando las causas primeras, fuentes o orígenes de las normas y reglas, confieren cohesión, coherencia y legitimidad a las normas jurídicas y al sistema jurídico como un todo. Son los principios generales del derecho (prima principia) que confieren al ordenamiento jurídico (tanto nacional como internacional) su ineluctable dimensión axiológica; son ellos que, en última instancia, proveen sus propios fundamentos. Es así como concibo la presencia y la posición de los principios en cualquier ordenamiento jurídico, y su rol en el universo conceptual del Derecho. De los prima principia emanan las normas y reglas, que en ellos encuentran su sentido. Los principios encuéntranse así presentes en los orígenes del propio Derecho. Los principios nos muestran los fines legítimos que buscar: el bien común (de todos los seres humanos, y no de una colectividad abstracta), la realización de la justicia (en los planos tanto nacional como internacional), el necesario primado del derecho sobre la fuerza, la preservación de la paz. Al contrario de los que intentan - a mi juicio en vano-minimizarlos, entiendo que, si no hay principios, tampoco hay verdaderamente un sistema jurídico. Sin los principios, el "orden jurídico" simplemente no se realiza, y deja de existir como tal". En "La Ampliación del Contenido Material del JUS COGENS" página 6. Publicado en la recopilación del XXXIV Curso de Derecho Internacional de la Organización de Estados Americanos. Disponible en: http://www.oas.org/es/sla/ddi/docs/publicaciones_digital_xxxiv_curso_derecho_internacional_2007_antonio_augusto_cancado_trindade.pdf 
1. Principio de desarrollo sostenible. GOROSITO ${ }^{23}$ establece que es el "principio de los principios" y que "sobre este principio se estructura hoy el paradigma dominante en el campo del Derecho Ambiental". El informe BRUNTLAND "Nuestro futuro común" establece que dicho principio es "aquel que atiende las necesidades del presente sin comprometer la capacidad de las generaciones futuras de atender sus propias necesidades". Para la instrumentación del principio de desarrollo sostenible es necesaria la aplicación de otros conceptos como la equidad intergeneracional, la aplicación de la perspectiva precautoria y el mantenimiento y protección de la diversidad e integridad biológicas.

2. Principio de prevención. ORTEGA ÁLVAREZ, citado por GOROSITO establece que "es fundamental en la actuación ambiental, debido al alto potencial de irreparabilidad de los daños ambientales". La evaluación de impacto ambiental sería una expresión práctica del principio de prevención. En la actualidad es notorio que la gran mayoría de Estados tienen previsiones normativas de derecho interno que establecen la obligatoriedad de una evaluación de impacto ambiental previa a la autorización de emprendimientos industriales o productivos que pudieran generar impactos al medio ambiente ${ }^{24}$. CAFFERATTA, citado por GOROSITO establece que el "principio de prevención, por otra parte, expande su influencia conformadora al propio sistema de responsabilidad por daño ambiental al otorgar la pauta esencial, que es aquella que enfatiza el rol prioritario de la prevención frente a la reparación". ${ }^{25}$

Por su parte, la Corte Interamericana de Derechos Humanos (en adelante CORTE IDH) ha establecido que "El principio de prevención de daños ambientales forma parte del derecho internacional consuetudinario"26. La CORTE IDH profundiza estableciendo que se pueden precisar ciertas obligaciones mínimas que los Estados deben adoptar dentro de su obligación de tomar medidas apropiadas para prevenir violaciones a los derechos humanos como consecuencia de daños ambientales: (i) deber de regulación; (ii) Obligación de supervisar y fiscalizar; (iii) Obligación de requerir y aprobar estudios de impacto ambiental27; iv) Deber de establecer un plan de contingencia; v) Deber de mitigar en casos de ocurrencia de daño ambiental.

En el mismo sentido se ha pronunciado la CIJ "La existencia de la obligación general de que los Estados velen por que las actividades realizadas dentro de su jurisdicción o bajo su control no dañen el medio ambiente de otros Estados o zonas que estén fuera de su jurisdicción nacional forma parte ya del corpus de normas internacionales en materia de medio ambiente $^{\prime 28}$. Posteriormente, la CIJ amplió su pronunciamiento en el caso de las

\footnotetext{
23 GOROSITO ZULUAGA, Ricardo. Los principios en el Derecho Ambiental. En: Revista de Derecho (UCU), no. 16 (2017), p. 101-136

24 Principio 21 de la Declaración de Estocolmo y Principio 2 de la Declaración de Rio.

25 Gorosito, Ricardo. Los principios en el Derecho Ambiental. En: Revista de Derecho (UCU), no. 16 (2017), p. 101-136

26 Opinión Consultiva CORTE IDH OC-23/17 párrafo 129.

27 La CORTE IDH ha señalado que los estudios de impacto ambiental deben realizarse conforme a los estándares internacionales y buenas prácticas al respecto: a. Llevarse a cabo antes de la realización de la actividad; b. Realizado por entidades independientes bajo la supervisión del Estado; c. Abarcar el impacto acumulado; d. Participación de las personas interesadas; e. Respetar tradiciones y cultura de los pueblos indígenas; f. Contenido de los Estudios de Impacto Ambiental definido legalmente.

28 Opinión consultiva de la Corte Internacional de Justicia sobre la legalidad de la amenaza o el empleo de armas nu-
} 
plantas de celulosa sobre el Río Uruguay (Argentina Vs. Uruguay), Sentencia de 20 de abril de 2010, párrafo 101 "The Court points out that the principle of prevention, as a customary rule, has its origins in the due diligence that is required of a State in its territory... A State is thus obliged to use all the means at its disposal in order to avoid activities which take place in its territory, or in any area under its jurisdiction, causing significant damage to the environment of another State. This Court has established that this obligation "is now part of the corpus of international law relating to the environment" 29 . En el caso Costa Rica vs Nicaragua, la CIJ reitera la necesidad de la evaluación de impacto ambiental al indicar: "Por las razones expuestas, la Corte concluye que Costa Rica no ha cumplido con la obligación que le incumbe en virtud del derecho internacional general de llevar a cabo una evaluación del impacto ambiental de la construcción de la carretera" ${ }^{\prime \prime}$.

3. Principio precautorio. La Declaración de Rio de Janeiro establece en su principio número 15 que "Con el fin de proteger el medio ambiente, los Estados deberán aplicar ampliamente el criterio de precaución conforme a sus capacidades. Cuando haya peligro de daño grave o irreversible, la falta de certeza científica absoluta no deberá utilizarse como razón para postergar la adopción de medidas eficaces en función de los costos para impedir la degradación del medio ambiente". La CIJ ha expresado que "Court considers that while a precautionary approach may be relevant in the interpretation and application of the provisions of the Statute, it does not follow that it operates as a reversal of the burden of proof ${ }^{\prime \prime 31}$. La interpretación de la Corte es importante ya que, a primera vista, parecería que el principio de precaución invierte la carga probatoria. ${ }^{32}$

\footnotetext{
cleares, párrafo 29.

29 Traducción libre: "La Corte señala que el principio de prevención, como norma habitual, tiene su origen en la diligencia debida que se requiere de un Estado en su territorio... Por lo tanto, un Estado está obligado a utilizar todos los medios a su alcance para evitar actividades que tienen lugar en su territorio, o en cualquier área bajo su jurisdicción, que causan daños significativos al medio ambiente de otro Estado. Esta Corte ha establecido que esta obligación "ahora forma parte del corpus del derecho internacional relacionado con el medio ambiente".

30 Corte Internacional de Justicia. Ciertas actividades realizadas por Nicaragua en la zona de la frontera, Costa Rica vs Nicaragua; construcción de un camino en Costa Rica al borde del río San Juan, párrafo 154. Citado por el Centro de Estudios en Derechos Humanos de la Universidad Autónoma de Yucatán, en el escrito de observaciones sobre la solicitud de Opinión Consultiva relativa a la interpretación de los artículos 1.1, 4.1 y 5.1 del Pacto de San José. Enero 2017 CARBALLO, CRUZ, GONZÁLEZ y RUBIO.

El Secretario General de las Naciones Unidas en el informe sobre "Lagunas en el derecho internacional del medio ambiente y los instrumentos relacionados con el medio ambiente: hacia un pacto mundial por el medio ambiente" informaba que "El principio de prevención está bien establecido como norma del derecho internacional consuetudinario, confirmada por la práctica pertinente en muchos tratados relativos al medio ambiente y los principales proyectos de codificación. En la práctica este principio se relaciona también con las obligaciones de diligencia debida, en particular la de realizar una evaluación del impacto ambiental antes de emprender actividades que entrañan un posible riesgo de daño transfronterizo". Documento A/73/419.

31 Traducción libre al español: "La Corte considera que si bien un enfoque de precaución puede ser relevante en la interpretación y aplicación de las disposiciones del Estatuto, no se deduce que funcione como una inversión de la carga de la prueba".

32 La posición de la CIJ es, ciertamente, opinable. "Una característica importante del principio precautorio es que incluye que se invierta la carga de la prueba, pues será quien pretende llevar a cabo una actividad cuestionada o incierta en cuanto a sus impactos sobre la naturaleza quien deberá demostrar con base en criterios técnicos y científicos que dicha actividad puede ser considerada sostenible". Centro de Estudios en Derechos Humanos de la Universidad Autónoma de Yucatán: Escrito de observaciones sobre la solicitud de Opinión Consultiva relativa a la interpretación de los artículos 1.1, 4.1 y 5.1 del Pacto de San José.

Elaborado por: Arturo Carballo Madrigal; María de los Ángeles Cruz Rosel; Andrea González Sánchez; Guillermo Rubio Herrera. Enero 2017. Página 33. Disponible en: http://www.corteidh.or.cr/sitios/observaciones/colombiaoc23/34_ua_ yucatan.pdf
} 
La CORTE IDH, cita un fallo del Tribunal Internacional del Derecho del Mar en el cual señalan que el enfoque de precaución ha iniciado una tendencia a formar parte del derecho internacional consuetudinario ${ }^{33}$. $^{34}$

4. Responsabilidades comunes pero diferenciadas. Este principio ha sido el ítem conductor de las negociaciones internacionales en la materia, por ejemplo de cambio climático. "Los países desarrollados reconocen la responsabilidad que les cabe en la búsqueda internacional de desarrollo sostenible, en vista de las presiones que sus sociedades ejercen el medio ambiente y de las tecnologías y los recursos financieros de que disponen" 35 .

5. Subsidiariedad. GOROSITO explica que este Principio apunta "básicamente a la promoción de la eficacia de las acciones de protección y de cumplimiento de las normas, evitando la burocratización y centralización de decisiones que terminan impidiendo la concreción en los hechos de los objetivos de ordenación y protección"36.

6. Solidaridad. La solidaridad constituye el punto de partida para la constatación del daño ambiental transfronterizo. SERVI nos enseña que "no es posible el aislamiento ambiental". Esta imposibilidad hace que sea necesaria la solidaridad internacional para compartir herramientas con el objetivo de resolver los problemas derivados de la contaminación.

7. No contaminar (o principio de contaminador pagador). TORRES LÓPEZ y ARANA GARCÍA expresan que más allá de su apariencia sancionadora, no se trata de un principio de tal carácter sino de un principio que incide en la prevención "Se trata de que contaminar no salga gratis, en el sentido de que no resulte, a priori, rentable (sino más bien lo contrario: que se presente como rentable no contaminar)". Por su parte SERVI se expresa en términos fuertes sobre la descripción que se realiza de este principio en la Declaración de Rio (Principio 16) "El principio no contaminar, surge como reacción a la increíble y a la vez paradójica recepción en la Declaración de Rio del principio "el que contamina paga. Este error u horror jurídico, atribuido a la presión ejercida por el establishment en la Conferencia de Rio 92, en realidad, ha servido para cristalizar en los instrumentos internacionales la cómoda y complaciente figura del "pagador-contaminador" extendida por toda la Tierra. La regla, la norma, debe ser no

33 Opinión Consultiva CORTE IDH OC-23/17 párrafo 177.

34 Con respecto al principio precuatorio, los "Principios de Oslo sobre obligaciones globales respecto al Cambio Climático" establecen que "a) El principio de Precaución requiere que: 1) las emisiones de GEI (gases de efecto invernadero) se reduzcan en la medida y al ritmo necesarios para proteger contra las amenazas del cambio climático que aún se pueden evitar; y 2) el nivel de reducción de las emisiones de GEI requerido para conseguirlo debe basarse en la peor de las situaciones posible que sea verosímil y realista y esté aceptada por un número sustancial de eminentes expertos en cambio climático. b) Las medidas requeridas por el Principio de Precaución tendrán que ser adoptadas sin importar el coste, a no ser que el coste sea totalmente desproporcionado respecto a la reducción en emisiones que podría comportar.

Sobre los Principios de Oslo: https: / globaljustice.yale.edu/oslo-principles-global-climate-change-obligations

35 GOROSITO ZULUAGA, Ricardo. Los principios en el Derecho Ambiental. En: Revista de Derecho (UCU), no. 16 (2017), p. 101-136 El preámbulo del Acuerdo de París establece que, las Partes "Deseosas de hacer realidad el objetivo de la Convención y guiándose por sus principios, incluidos los principios de la equidad y de las responsabilidades comunes pero diferenciadas y las capacidades respectivas, a la luz de las diferentes circunstancias nacionales... han convenido lo siguiente:"

36 GOROSITO ZULUAGA, Ricardo. Los principios en el Derecho Ambiental. En: Revista de Derecho (UCU), no. 16 (2017), p. 101-136. 
contaminar y la excepción que confirma la regla es la posibilidad de contaminar pero en determinadas condiciones perfectamente reguladas y bajo el control de gestión de la autoridad de aplicación responsable" ${ }^{\prime 37}$.

8. Cooperación. La Declaración de Rio sobre Medio Ambiente y el Desarrollo establece que "los Estados deberán cooperar con espíritu de solidaridad mundial para conservar, proteger y restablecer la salud y la integridad del ecosistema de la Tierra". La CIJ concluye que el Principio de Cooperación se deriva del principio de buena fe "the mechanism for co-operation between States is governed by the principle of good faith. Indeed, according to customary international law, as reflected in Article 26 of the 1969 Vienna Convention on the Law of Treaties, "[e]very treaty in force is binding upon the parties to it and must be performed by them in good faith"38.

La CORTE IDH "considera que los Estados tienen la obligación de cooperar, de buena fe, para la protección contra daños al medio ambiente ${ }^{\prime \prime 39}$. La CORTE IDH establece que el derecho internacional ha precisado los siguientes deberes específicos que son exigibles a los Estados, en materia ambiental, para el cumplimiento de esta obligación: 1) el deber de notificación: "Esta obligación ha sido reconocida por la jurisprudencia internacional como una obligación de derecho internacional consuetudinario... Esta Corte considera que los Estados deben notificar a otros Estados potencialmente afectados sobre posibles daños ambientales transfronterizos significativos al momento en que conozcan de la posibilidad de dicho riesgo. Esto, en algunos casos, será previo a la realización del estudio de impacto ambiental, por ejemplo, como resultado de un estudio inicial o por el tipo de actividad, y en otros casos solo surgirá luego de una determinación en este sentido por parte de un estudio de impacto ambiental." "40 2) el deber de consultar y negociar con los Estados potencialmente afectados "La obligación de negociar no implica la obligación de llegar a un acuerdo. Si las partes no llegan a un acuerdo, deben acudir a los mecanismos de solución pacífica de las controversias, sea por medios diplomáticos o judiciales" 41 . Este deber dentro del Principio de Cooperación necesariamente exige una interpretación en conjunto con los Principios de Prevención y Precaución. 3) intercambio de información entre Estados de conocimientos científicos y tecnológicos (de acuerdo a la CORTE IDH, esta obligación no tiene carácter consuetudinario y estará sujeta al derecho convencional, si existiera un tratado que regulara el caso concreto).

9. Principio de no regresión y progresividad. El Secretario General de las Naciones Unidas define a este principio en los siguientes términos que compartimos " $E l$ principio de no regresión es relativamente nuevo en el ámbito del derecho ambiental, si bien en los sistemas que protegen los derechos humanos y el derecho laboral se entiende

37 SERVI, Aldo. El Derecho Ambiental Internacional. Revista de Relaciones Internacionales Nro 14.

38 Caso de las plantas de celulosa sobre el Río Uruguay (Argentina Vs. Uruguay), Sentencia de 20 de abril de 2010 , párrafo 145. "El mecanismo de cooperación entre los Estados se rige por el principio de buena fe. De hecho, de acuerdo con el derecho internacional consuetudinario, como se refleja en el artículo 26 de la Convención de Viena sobre el derecho de los tratados de 1969 , "todo tratado en vigor es vinculante para las partes y debe ser cumplido por ellos de buena fe". Traducción libre al español.

39 Opinión Consultiva CORTE IDH OC-23/17 párrafo 185.

40 Opinión Consultiva CORTE IDH OC-23/17 párrafos 188 y 193.

41 Opinión Consultiva CORTE IDH OC-23/17. 
bien la idea de no permitir retrocesos sobre la que se sustenta el principio. La idea de que, una vez que un derecho humano ha sido reconocido, este no puede ser coartado, destruido ni derogado es común a todos los principales instrumentos internacionales de derechos humanos. El corolario del principio de no regresión es el principio de progresividad. La no regresión tiene por objeto garantizar que la protección ambiental no se ve debilitada, mientras que la progresividad aspira a mejorar la legislación ambiental, incluso mediante el incremento del nivel de protección, sobre la base de los conocimientos científicos más recientes. El Acuerdo de París es explícito a este respecto y dispone, en su artículo 4, párrafo 3, que cada contribución determinada a nivel nacional sucesiva "representará una progresión con respecto a la contribución determinada a nivel nacional que esté vigente para esa Parte y reflejará la mayor ambición posible de dicha Parte"42.

ROHR, en opinión que compartimos, nos enseña que "nada impide que un tratado derogue una norma consuetudinaria entre las partes ni que una regla consuetudinaria derogue un tratado, siempre a condición que tengan el mismo ámbito de validez material y personal, por lo que no podrá aplicarse automáticamente cuando las partes en el tratado posterior no sean idénticas a las partes en el tratado anterior" ${ }^{\prime 43}$.

6. Pruebas relevadas a través de investigación sobre el cumplimiento de los requisitos exigidos para considerar una norma internacional de protección del medio ambiente como una norma imperativa de derecho internacional (ius cogens).

En el texto de proyecto de conclusiones y del proyecto de anexo aprobados provisionalmente por el Comité de Redacción de la Comisión de Derecho Internacional de las Naciones Unidas, en primera lectura, de fecha 24 de mayo de 2019, posteriormente adoptado por dicha Comisión ${ }^{44}$, se establecen ciertos mecanismos probatorios de la aceptación y el reconocimiento del carácter imperativo de una norma de derecho internacional general (ius cogens).

6.1 Medios probatorios principales de aceptación y reconocimiento. El "proyecto de conclusión 8" establece que:

1. La prueba de la aceptación y el reconocimiento de que una norma de derecho internacional general es una norma imperativa (ius cogens) puede adoptar una gran variedad de formas.

2. Esas formas de prueba comprenden, sin reducirse a ello:

a) las declaraciones públicas hechas en nombre de los Estados;

b) las publicaciones oficiales;

42 "Lagunas en el derecho internacional del medio ambiente y los instrumentos relacionados con el medio ambiente: hacia un pacto mundial por el medio ambiente" Documento A/73/419.

43 En: La responsabilidad internacional del Estado por violación al jus cogens / Aldana Rohr. - 1a ed . - Avellaneda : SGN Editora, 2015. Página 11.

44 Disponible en: https://undocs.org/es/A/CN.4/L.936 
c) los dictámenes jurídicos gubernamentales;

d) la correspondencia diplomática;

e) los actos legislativos y administrativos;

f) las decisiones de las cortes y tribunales nacionales;

g) las disposiciones de los tratados;

h) las resoluciones aprobadas por una organización internacional o en una conferencia intergubernamental.

A los efectos de claridad didáctica se separaron los medios probatorios en los literales a) a h). Es menester indicar que la comprobación del carácter de ius cogens de una norma es una tarea compleja, principalmente porque los principales actores que tienen la potestad de producir dichos medios probatorios, los Estados y las Organizaciones Internacionales, son renuentes a la hora de expresarse categóricamente sobre el carácter imperativo de una norma. Es más común, que, una vez declarada la existencia de una norma imperativa de derecho internacional, por ejemplo, por un órgano jurisdiccional internacional (en particular la CIJ) los Estados comiencen a realizar mayores manifestaciones sobre dichas normas, como normas ius cogens.

Por el alcance del presente trabajo, no se realizará un estudio sobre la pertinencia y eficacia de los medios probatorios que son sugeridos por la Comisión de Derecho Internacional, pero entendemos que es un punto que es necesario profundizar a nivel académico.

En el asunto que nos convoca, y durante el tiempo que se ha tenido para realizar el presente trabajo de investigación, se han podido recabar las siguientes pruebas:

1. En relación a los literales a) las declaraciones públicas hechas en nombre de los Estados; y b) las publicaciones oficiales; se recabó la comunicación realizada por la Misión Permanente de la República Federal Alemana ante las Naciones Unidas, en ocasión a la respuesta enviada a la Comisión de Derecho Internacional en la sexagésima séptima sesión (año 2015). En dicha comunicación, Alemania incorpora oficialmente a través de su representación ante Naciones Unidas, las consideraciones realizadas por la Corte Constitucional Federal de Alemania donde expresamente se enumeran ciertas normas como ius cogens, entre ellas "las normas centrales para la protección del medio ambiente" 45 .

2. En relación al literal f) las decisiones de las cortes y tribunales nacionales ${ }^{46}$; se recabaron dos sentencias que mencionan a las normas de protección del medio ambiente como normas ius cogens (Alemania y Colombia).

45 Disponible en: https://legal.un.org/docs/?path=../ilc/sessions/68/pdfs/english/jc_germany.pdf\&lang=E (ver página 2).

46 Sobre este punto, será interesante darle un seguimiento al estado del litigio en materia de cambio climático en los próximos años. El Programa de las Naciones Unidas para el Medio Ambiente, realizó en mayo de 2017 un interesante relevamiento sobre "El estado del litigio en materia de Cambio Climático - una revisión global" en cooperación con el Sabin Center for Climate Change Law de la Columbia Law School. 


\section{Alemania:}

La Corte Constitucional Federal de Alemania, en una sentencia del año 2004 realizó unos comentarios sobre la característica y contenido del ius cogens:

"In Article 1.2 and Article 25 sentence 1 the [German] Basic Law ["Grundgesetz"],[ .. . ] also adopts the gradual recognition of the existence of mandatory provisions, that is, provisions that are in the individual case not open to disposition by the states (ius cogens). These are rules of law which are firmly rooted in the legal conviction of the community of states, which are indispensable to the existence of public international law, and the compliance with which all members of the community of states may require [ ... ]. This relates in particular to provisions on the international maintenance of peace, the right of self-determination, fundamental human rights and central norms for the protection of the environment [ ... ]. Such public international law may not be excluded by[ ... ] states either unilaterally or by agreement, but only altered by a later norm of general international law of the same legal nature[ ... ]. ${ }^{47}$ Los destacados nos pertenecen.

\section{Colombia:}

La Corte Suprema de Justicia de la República de Colombia, en una sentencia del año 2018 estableció que "11.3. La anterior realidad, además de transgredir las regulaciones atinentes a la Carta Ambiental patria, y los instrumentos internacionales que integran el orden público ecológico mundial, constituye un grave desconocimiento de las obligaciones adquiridas por el Estado en la Convención Marco sobre Cambio Climático de París de 2015, en donde Colombia, entre otras responsabilidades, se comprometió a reducir la "deforestación en la Amazonía Colombiana", cuyo objeto consistía en reducir a cero la deforestación en esa región para el año 2020, pues de lograrlo, según el Ministerio de Ambiente y Desarrollo Sostenible, “(...) 44 megatoneladas de gases de efecto invernadero no entrarían en la atmósfera, y 100 mil hectáreas agropecuarias en áreas de alta deforestación serían más amigables con el medio ambiente". ${ }^{48}$ Los destacados nos pertenecen.

3. En relación al literal g) las disposiciones de los tratados, podremos mencionar que existen una gran cantidad de disposiciones en tratados multilaterales de protección del medio ambiente que declaran normas consuetudinarias. Excede ampliamente el objeto de estudio del presente trabajo analizar todas las disposiciones que podrían ingresar en este ítem. Se recomienda, por ejemplo, la enumeración de tratados que enumera Aldo SERVI en la publicación de Thomson Reuters "Derecho ambiental: Responsabilidad ambiental internacional" (punto número IX) ${ }^{49}$.

\footnotetext{
47 Fragmentos de la referida sentencia pueden encontrarse en la comunicación realizada por la Misión Permanente de la República Federal Alemana ante las Naciones Unidas, en ocasión a la respuesta enviada a la Comisión de Derecho Internacional en la sexuagésima séptima sesión (año 2015), página 2. Disponible en https://legal.un.org/docs/?path=../ilc/ sessions/68/pdfs/english/jc_germany.pdf\&lang=E Traducción libre: "En el Artículo 1.2 y en la primer oración del Artículo 25, la Ley Fundamental [alemana] ["Grundgesetz"], [... ] también adopta el reconocimiento gradual de la existencia de disposiciones obligatorias, es decir, disposiciones que, en el caso individual, no están a disposición de los estados (ius cogens). Estas son normas de derecho firmemente arraigadas en la convicción legal de la comunidad de estados, que son indispensables para la existencia del derecho internacional público y el cumplimiento que todos los miembros de la comunidad de estados pueden requerir [...].Esto se refiere en particular a las disposiciones sobre el mantenimiento internacional de la paz, el derecho a la libre determinación, los derechos humanos fundamentales y las normas centrales para la protección del medio ambiente [...]. Este derecho internacional público no puede ser excluido por [...] los estados, ya sea unilateralmente o por acuerdo, sino solo alterado por una norma posterior de derecho internacional general de la misma naturaleza legal [...]."

48 Corte Suprema de Justicia de Colombia. Sala Casación Civil. STC4360-2018. Página 38. Disponible en: http://www. cortesuprema.gov.co/corte/wp-content/uploads/2018/04/STC4360-2018-2018-00319-011.pdf

49 Entre otros: Convenio sobre Responsabilidad civil en materia de energía termonuclear; Convención sobre la Respon-
} 
6.2 Medios probatorios auxiliares de aceptación y reconocimiento. En el proyecto de conclusión 9 del texto de proyecto de conclusiones y del proyecto de anexo aprobados provisionalmente por el Comité de Redacción de la Comisión de Derecho Internacional de las Naciones Unidas, en primera lectura, de fecha 24 de mayo de 2019, posteriormente adoptado por dicha Comisión de Derecho Internacional ${ }^{50}$, se establecen los "Medios auxiliares de determinación del carácter imperativo de las normas de derecho internacional general (ius cogens)". Dichos medios auxiliares son los siguientes:

1. Las decisiones de cortes y tribunales internacionales (en particular la Corte Internacional de Justicia).

2. La labor de:

a) Órganos de expertos establecidos por Estados o por organizaciones internacionales.

b) La doctrina de los publicistas de mayor competencia de las distintas naciones.

En el asunto que nos convoca, y durante el tiempo que se ha tenido para realizar el presente trabajo de investigación, se han podido recabar las siguientes pruebas de medios auxiliares de determinación:

1. Las decisiones de cortes y tribunales internacionales (en particular la Corte Internacional de Justicia).

Orgánicamente la CIJ no se ha pronunciado sobre si algunas de las normas de protección del medio ambiente poseen actualmente el carácter de ius cogens.

Sin embargo, en algunas oportunidades, Magistrados de la CIJ, en opiniones disidentes o coincidentes, sí han abordado la temática, por lo menos tangencialmente.

Por ejemplo, en el asunto "Certain Activities Carried Out by Nicaragua in the Border Area (Costa Rica v. Nicaragua) Compensation Owed by the Republic of Nicaragua to the Republic of Costa Rica", en opinión disidente, el Magistrado ad hoc Dugard estableció que "La obligación de no proceder a una deforestación ilícita que provoque la liberación de carbono en la atmósfera y obstaculice el secuestro de gases es sin duda una obligación erga omnes".

En opinión separada, en el fallo del asunto Gabcikovo-Nagymaros Project (Hungary v. Slovakia), el Magistrado Weeramantry, ingresa a la temática a través de la protección

sabilidad de los explotadores de buques nucleares; Convención sobre Responsabilidad por daños nucleares; Convenio sobre Responsabilidad civil por daños causados por la contaminación de las aguas del mar por hidrocarburos; Convenio sobre Constitución de un fondo de indemnización de daños causados por la contaminación de hidrocarburos; Convención de Viena sobre Responsabilidad civil en la esfera de transporte marítimo de sustancias nucleares; Convención Internacional para prevención de contaminación de buques; Convención sobre el Comercio Internacional de especies amenazadas de fauna y flora silvestre; Convención sobre la Responsabilidad civil por daños de contaminación por hidrocarburos resultantes de la exploración y explotación de los recursos del fondo del mar; Convenio para la Protección de la capa de ozono; Convenio sobre Pronta notificación de accidentes nucleares; Convenio sobre Asistencia en caso de accidente nuclear o emergencia radiológica; Protocolo al Tratado antártico sobre protección del ambiente marino; Protocolos sobre sustancias que afectan la capa de ozono; Convención Marco sobre Cambio Climático; Convención sobre diversidad biológica; Convención sobre Desertificación; Acuerdo de París etc.

50 Disponible en: https://undocs.org/es/A/CN.4/L.936 
del medio ambiente como derecho humano estableciendo que "La protección del medio ambiente es también una parte esencial de la doctrina contemporánea de los derechos humanos, ya que es una condición sine qua non para la efectividad de numerosos derechos humanos como el derecho a la salud y el propio derecho a la vida. Apenas es necesario profundizar en esta cuestión, ya que los daños al medio ambiente pueden poner en peligro y socavar todos los derechos humanos enunciados en la Declaración Universal y en otros instrumentos de derechos humanos".

La Corte Interamericana de Derechos Humanos se ha expresado enumerando una serie de obligaciones internacionales de los Estados con relación a la protección medioambiental. En la opinión consultiva OC 23-17 se realizan una serie de conclusiones que nos parece relevante transcribir: "Los Estados tienen la obligación de prevenir daños ambientales significativos, dentro o fuera de su territorio"; "Con el propósito de cumplir la obligación de prevención los Estados deben regular, supervisar y fiscalizar las actividades bajo su jurisdicción que puedan producir un daño significativo al medio ambiente"; "Los Estados deben actuar conforme al principio de precaución... aún en ausencia de certeza científica"; "Los Estados tienen la obligación de cooperar, de buena fe, para la protección contra daños al medio ambiente"; "deben notificar a los demás Estados potencialmente afectados"; "obligación de garantizar el derecho al acceso a la información relacionada con posibles afectaciones al medio ambiente"; "garantizar el derecho a la participación pública de las personas bajo su jurisdicción"; "garantizar el acceso a la justicia, en relación con las obligaciones estatales para la protección del medio ambiente que han sido enunciadas".

En el punto número 115 de la OC 23-17 se establece que "Esta Corte ha sostenido que, en aplicación del artículo 1.1 de la Convención, los Estados poseen la obligación erga omnes de respetar y garantizar las normas de protección, así como de asegurar la efectividad de los derechos humanos" posteriormente agrega que "Estas obligaciones deben ser interpretadas tomando en cuenta las obligaciones y principios de derecho ambiental".

Es menester señalar que en toda la opinión consultiva OC 23-17 no se menciona el término ius cogens. Sí se trae a colación que en una oportunidad anterior la Corte IDH se pronunció estableciendo el carácter de norma imperativa de derecho internacional general, al derecho de acceso a la justicia. Con distintas integraciones la Corte IDH quizás haya sido mucho más abierta a denominar una norma como de ius cogens.

Consideramos que en la opinión consultiva OC 23-17, la CORTE IDH enumeró sustancialmente una serie de obligaciones de los Estados (cuyas fuentes enumeradas son los tratados, la costumbre e inclusive, al decir de la Corte, "el soft law"), asignándoles quizás una jerarquía superior a cualquier pacto en contrario, pero sin llegar a nombrar claramente dichas normas como imperativas de derecho internacional general. Entendemos que se perdió una oportunidad inmejorable de contribuir con el desarrollo progresivo del derecho internacional.

2. Con relación a la labor de "órganos de expertos establecidos por Estados o por organismos internacionales", se ha recabado la siguiente prueba:

En 1976, la Comisión de Derecho Internacional en el tratamiento del estudio sobre el tema de la responsabilidad de los Estados, sostuvo que las normas de derecho interna- 
cional general relativas a la protección del medio humano "sólo pueden presentarse en gran medida, para la comunidad internacional en su conjunto, como normas imperativas. Y parece no menos indiscutible que las obligaciones dimanantes de esas normas tienen por objeto la salvaguardia de intereses tan vitales para la comunidad internacional que una violación de tales obligaciones no puede por menos de ser considerada por todos los componentes de esa comunidad como un hecho internacionalmente ilícito particularmente grave, como un crimen internacional"51.

\section{La doctrina de los publicistas de mayor competencia de las distintas naciones.}

A continuación, transcribiremos opiniones de distintos juristas (en su mayoría latinoamericanos) quienes caracterizan a las normas de protección del medio ambiente como normas imperativas de derecho internacional general - ius cogens.

Manuel PEREZ GONZÁLEZ enseña que "Entre los principios "sectoriales" con categoría de ius cogens cabe citar, a título de ejemplo, algunos pertenecientes al ius in bello (principio de distinción, prohibición de causar daños superfluos a los combatientes, principios enunciados en el art. 3 común a los cuatro convenios de Ginebra de 1949), a la responsabilidad penal internacional del individuo (algunos de los principios de Nuremberg y de los recogidos en la Parte III del Estatuto de la Corte Penal Internacional), al Derecho del medio ambiente (principio de utilización no lesiva de territorio, principio de prevención), al Derecho de los diversos espacios (principio del patrimonio común de la humanidad), etcétera" ${ }^{52}$

Por su parte, Mariana BLENGIO VALDÉS opina que "La preocupación por el medio ambiente. Jus Cogens. Del punto de vista del Derecho Internacional se ha sostenido que la preocupación por el medio ambiente y el deber de protección del mismo tal cual emana de las Conferencias de Estocolmo, Río y Johannesburgo antes referidas, constituye uno de los casos de jus cogens, es decir de normas imperativas de Derecho Internacional general aceptadas por la Comunidad Internacional en su conjunto". ${ }^{53}$

Zlata DRNAS de CLÉMENT restringe la caracterización de ius cogens a la prohibición de una agresión deliberada al medio ambiente, explicando que "En relación a la naturaleza de la norma protectora del medio ambiente contra todo acto deliberado no justificado por necesidad militar ineludible, entendemos constituye una norma consuetudinaria de carácter superior (aún cuando pueda estar contenida en normas convencionales), intransgredible, inderogable, perentoria, coactiva, de jus cogens. $Y$, por tratarse de norma de tal tipo, es contraída frente a la comunidad internacional en su conjunto (erga omnes), cabiendo, en caso de violación, sanciones internacionales de carácter particular a través del ejercicio de distintas formas de jurisdicción penal internacional." 54 Esta opinión es compartida por Luciano

51 Anuario de la Comisión de Derecho Internacional 1976. Vol. II (segunda parte) Naciones Unidas, Nueva York 1977, página 108. Citado por Luciano Pezzano en "Responsabilidad Internacional Ambiental por conflicto Armado" página 12. 52 PEREZ GONZÁLEZ, Manuel "Apuntes sobre los principios generales del derecho en el Derecho internacional” artículo en "Soberanía del Estado y Derecho Internacional" Homenaje al Profesor Juan Antonio Carrillo Salcedo. Servicio de Publicaciones de la Universidad de Sevilla, año 2005, página 1031.

53 BLENGIO VALDÉS, Mariana. “El derecho humano a un medio ambiente sano". Revista de derecho de la Universidad de Montevideo, página 10.

54 DRNAS de CLÉMENT, Zlata "El daño deliberado y substancial al medio ambiente, como objetivo, medio o método de guerra constituye violación de norma imperativa de derecho internacional general", página 28. Disponible en: https:/ / www.icrc.org/es/doc/assets/files/other/10_zlata.pdf 
PEZZANO "Ello confirma nuestra apreciación, que compartimos con Drnas de Clément de que un ataque dirigido contra el medio ambiente en conflicto armado no justificado por la necesidad militar es una violación del ius cogens y, por lo tanto, un crimen internacional". ${ }^{55}$

Dentro de los autores que de forma más contundente se han expresado, se encuentra Aldo SERVI quien opina que:

"Adherimos a la doctrina que postula la existencia en el Derecho Internacional Ambiental de la vigencia de una norma de derecho internacional general (ius cogens) que prohíbe a los Estados realizar o consentir la realización en su territorio por personas o entidades sometidas a su jurisdicción de actos que puedan causar daños al territorio de otros Estados o a sus nacionales"

"Donde no está legislado, es decir donde no haya acuerdo o convención, desde la óptica del derecho ambiental internacional y del paradigma del desarrollo sostenible, en casos de actividades peligrosas o ultrapeligrosas, también habrá responsabilidad internacional de carácter ambiental, por el principio del derecho internacional público general ius cogens, ya mencionado, porque resulta imposible distinguir en materia de responsabilidad ambiental la contaminación operacional de la provocada con culpa o dolo. Y resulta imposible distinguirlas porque nadie contamina por contaminar."

“Existe en derecho internacional alguna norma no convencional, es decir consuetudinaria, que prohíba a los Estados realizar o consentir la realización en su territorio, por personas o entidades sometidas a su jurisdicción, de actos que puedan causar daños a otros Estados o a los nacionales de otros Estados? Sí, la respuesta es sí. Y la norma es ius cogens."

"Además, la norma ambiental internacional es "ius cogens" una norma imperativa de carácter internacional que no puede ser dejada de lado sino por otra norma de la misma naturaleza (Agenda XXI y Declaración de Rio). ${ }^{57}$

Andrés TÉLLEZ-NÚÑEZ en una muy interesante investigación expone que "Los hallazgos de la Comisión de Derecho Internacional especificamente y las connotaciones propias de la disciplina, muestran que en efecto sí podría y debería hablarse hoy de normas imperativas referidas al cuidado del medio ambiente que se evidencien en una asunción de responsabilidad internacional por parte de los Estados y que incluso, permitan más allá del artículo 26 de la Convención de Viena de 1969 (pacta sunt servanda) exigir la implementación de acciones y mecanismos que garanticen el derecho a la vida de todos los seres humanos del planeta en un contexto, que de acuerdo con lo expuesto aquí, tendría al respeto por la más válida de las normas que es la naturaleza misma, como algo fundamental."58

La recomendación número 4 del Centro Internacional de Derecho Comparado del Ambiente del año 2011, resolvió en la tercera Reunión Mundial de Juristas y Asocia-

55 PEZZANO, Luciano, en "Responsabilidad Internacional Ambiental por conflicto Armado" página 19.

56 SERVI, Aldo. "Derecho Ambiental: Responsabilidad Ambiental Internacional” Thomson Reuters.

57 SERVI Aldo, “El Derecho Internacional Ambiental” Revista de Relaciones Internacionales Nro. 14.

58 TÉLLEZ-NÚÑEZ, Andrés. "Lo justo ambiental en el contexto de normas imperativas de derecho internacional público". Revista de la facultad de derecho y ciencias sociales. UPB. Página 356. 
ciones de Derecho Ambiental que se recomienda "Reconocer que el derecho al medio ambiente, de la misma manera que sus principios fundadores pertenecen al ius cogens internacional, entendido como una norma imperativa de Derecho Internacional general universalmente aceptada y reconocida por la sociedad internacional".

Kornicker UHLMAN "llega a la conclusión de que, si bien la prohibición de infligir daños graves y deliberados al medio ambiente durante los conflictos armados es una norma de ius cogens, la prohibición general de causar o no prevenir daños ambientales que amenacen a la comunidad internacional en su conjunto aún no ha alcanzado plenamente el rango de ius cogens" 59

Por su parte, Ricardo GOROSITO expresa que "La manifestación de voluntad que explicitó los Principios del Derecho Ambiental, desde Estocolmo, se tradujo en normas de Derecho Internacional, aunque originariamente normas de soft law, pero normas, que luego, por los mecanismos propios de su refrenda universal y aceptación en tratados y praxis, han adquirido la condición objetiva de normas de jus cogens." 60

La opinión calificada de DIEZ DE VELASCO expresa que "La función social primordial de este principio (solidaridad) es establecer restricciones objetivas a la voluntad particular de los Estados, esto es, al libre desenvolvimiento de la estructura relacional, mediante normas de derecho imperativo o perentorio (ius cogens) que pretenden reflejar la protección jurídica de intereses colectivos esenciales para la C.I. en su conjunto, centrados en la prohibición de la agresión y en la defensa del principio de libre determinación y de ciertos derechos y libertades fundamentales para la salvaguarda de la persona y el medio humano (prohibición del genocidio, la esclavitud, la discriminación racial y la contaminación masiva del medio ambiente)"61.

Nuestro Profesor, Dr. Roberto PUCEIRO RIPOLL ${ }^{62}$ realiza una clasificación de las normas ius cogens entre "Normas que protegen los intereses y los valores de la comunidad como tal"63, dentro de las cuales cabría incluir "las que establecen que los fondos marinos y oceánicos y su subsuelo fuera de los límites de la jurisdicción nacional, así como sus recursos, son patrimonio común de la humanidad; el principio de que la exploración o utilización del espacio ultraterrestre o los cuerpos celestes deben ser realizados en provecho y en interés de la humanidad y pertenecen a toda ella, y la defensa del medio ambiente", "Normas que protegen los derechos de los Estados como tales y en sus relaciones recíprocas, en tanto que miembros de la sociedad internacional"64 $y$ "Normas que protegen los derechos fundamentales de las personas en su proyección humanitaria y universal"65.

59 La opinión de UHLMAN es interpretada por el Relator Especial para las normas ius cogens de la Comisión de Derecho Internacional. Documento A_CN.4_727 página 68 referencia a pie de página número 416.

60 GOROSITO ZULUAGA, Ricardo. Los principios en el Derecho Ambiental. En: Revista de Derecho (UCU), No. 16 (2017), página 10. Disponible en http:/ / www.scielo.edu.uy/pdf/rd/n16/2393-6193-rd-16-00101.pdf

61 DIEZ DE VELASCO, Manuel. Instituciones de Derecho Internacional Público. Undécima edición, página 74.

62 PUCEIRO RIPOLL, Roberto. "Las normas de Jus Cogens en el campo del derecho internacional contemporáneo". En "Derecho Internacional Público" Tomo 1, Jiménez de Aréchaga, Arbuet-Vignali y Puceiro Ripoll. Fundación de Cultura Universitaria. Primera edición, noviembre 2005. Páginas 378 y 379.

63 Incluye a las siguientes normas: interdicción del uso y la amenaza de la fuera; el aseguramiento del mantenimiento de la paz; el derecho al desarrollo económico, social y cultural; represión de piratería; y la libertad de alta mar".

64 Incluye a las siguientes normas: normas que establecen la soberanía y la libre determinación de los Estados; igual soberana y el principio de la no intervención.

65 Incluye a las siguientes normas: normas que proscriben la discriminación racial; la supresión de la esclavitud, el genocidio, la trata de mujeres, niños y seres humanos. 
Por último, es necesario mencionar el excelente trabajo realizado por el Dr. Jorge VIÑUALES en el año 2008, publicado en la Revista Colombiana de Derecho Internacional $\mathrm{N}^{\mathrm{o}} 13$. El Dr. Viñuales realiza un estudio sobre la protección del medio ambiente y su jerarquía internacional. La publicación de dicho trabajo es anterior a las últimas recomendaciones de la Comisión de Derecho Internacional sobre las normas imperativas de Derecho Internacional. En concreto, el Profesor Viñuales concluye, entre otros interesantes puntos que "En el estado actual del derecho internacional, tanto los Estados como las jurisdicciones internacionales muestran cierta reticencia ante la posibilidad de calificar el principio de protección medioambiental como norma de jus cogens. Dicha reticencia es menor con respecto a la calificación de dicho principio como obligación erga omnes, sin duda a causa de las diversas implicancias de uno y otro concepto. Por último, la calificación como interés esencial no parece presentar inconveniente alguno, al menos luego de la decisión de la C.I.J. en el caso Gabcikovo-Nagymaros". Coincidimos plenamente con la apreciación del Dr. Viñuales en cuanto a que es necesario un "esclaracimiento conceptual de las relaciones entre los tres conceptos" (ius cogens, obligaciones erga omnes e intereses esenciales) y en cuanto a que "la vieja idea de un órden público internacional posee actualmente los medios institucionales para afirmarse"66.

\section{COMENTARIOS Y ARGUMENTACIÓN JURÍDICA.}

En el presente capítulo se tomarán en cuenta los principales principios de derecho internacional ambiental que han sido reconocidos, al menos, como derecho internacional consuetudinario por una Corte Internacional (sea por ejemplo, la CIJ o CORTE IDH). Como se ha expresado más arriba, son fuentes de normas ius cogens el derecho consuetudinario y los principios generales de derecho ${ }^{67}{ }^{68}$. Las normas convencionales no constituyen, en sí, normas de derecho internacional general capaces de ser fuente de normas de ius cogens, pero pueden reflejar normas de derecho internacional general que eventualmente pueden alcanzar el rango de ius cogens.

Ciertos principios han sido declarados judicialmente como derecho consuetudinario. De acuerdo a lo investigado en el presente estudio, hasta el momento hay pocos medios principales de comprobación en los cuales basarse para calificar a las normas de protección del medio ambiente como normas imperativas de derecho internacional general. Sí se ha logrado recabar prueba a través de medios auxiliares de comprobación (principalmente doctrina).

Los principios de prevención, precautorio y de cooperación internacional en temas de medio ambiente han sido declarados judicialmente como normas internacionales consuetudinarias.

66 VIÑUALES, Jorge. "La protección del medio ambiente y su jerarquía normativa en derecho internacional". Revista Colombiana de Derecho Internacional No 13 , páginas 11 a 44 . ISSN: 1692-8156.

67 "Una norma de derecho internacional consuetudinario no surgirá si entra en conflicto con una norma imperativa de derecho internacional general (ius cogens). Una norma de derecho internacional consuetudinario que no tenga carácter de ius cogens dejará de existir si surge una nueva norma imperativa de derecho internacional general (ius cogens) que entre en conflicto con ella". A/ CN4.714 página 64.

68 El Relator Especial Dire Tladi, en opinión que compartimos, concluye que "la objeción persistente a la formación de una norma de derecho internacional consuetudinario no puede impedir la aparición de una norma de ius cogens" A/CN4.714 página 63. Comparte esta posición Rohr: "Cuando se trate de una costumbre universal, que además sea de jus cogens, la regla del objetor persistente no es aplicable", La responsabilidad internacional del Estado por violación al jus cogens / Aldana Rohr. - 1a ed . - Avellaneda: SGN Editora, 2015. Página 19. 
Estos tres principios han sido reflejados en normas convencionales, tanto bilaterales como multilaterales. Principalmente a través de las obligaciones contraídas en tratados multilaterales, en varios países han comenzado una serie de juicios accionados por ciudadanos contra sus propios Estados (en el fuero doméstico) donde solicitan a la Justicia que se pronuncie sobre las obligaciones que emanan de dichos acuerdos internacionales $\mathrm{y}$, en definitiva, fallar, por ejemplo, a favor de que el Estado reduzca drásticamente la emisión de gases de efecto invernadero (en adelante GEI).

La cantidad de casos ha ido en aumento y recientemente, el Tribunal Supremo de los Países Bajos falló a favor de la organización no gubernamental URGENDA en su demanda contra el Estado neerlandés, con el objetivo de que se reduzcan en un 25\% las emisiones de GEI para finales del año $2020^{69}$.

Aún a nivel internacional el nivel litigioso es muy bajo, las normas de protección del medio ambiente han estado presentes en distintos fallos de la CIJ, pero siempre insertos en la disyuntiva entre desarrollo económico y protección del medio ambiente, que inevitablemente permea la interpretación del derecho. Ante la poca casuística, me propongo imaginar un serie de hechos para testear el estado del derecho internacional al día de hoy.

Imaginemos por un momento que existen dos estados ficticios, sólo a los efectos de hacer este ejercicio interpretativo. Los gobiernos de los Estados "Alfa" y "Beta" son fervientes negadores del cambio climático. Tan es así, que, a pesar de que las anteriores administraciones habían firmado y ratificado el acuerdo de París del año 2015, ambos deciden denunciar dicho tratado aplicando el artículo $28^{70}$. Transcurrido un año desde que el Depositario recibió la notificación correspondiente, ambos estados ya no son parte del Acuerdo de París.

Ambos Estados saben que, al día de hoy, varios de los principios que fueron incorporados en el Acuerdo de París, a su vez han sido reconocidos como normas consuetudinarias y que existe una corriente doctrinaria importante y jurisprudencia incipiente que establece que las normas de protección del medio ambiente son normas imperativas de derecho internacional - ius cogens. Ante esta situación, rápidamente intentan bloquear cualquier posible injerencia sobre su potestad normativa. Firman y ratifican un tratado entre ambos estableciendo que, por ejemplo, para autorizar proyectos industriales de gran porte, no son necesarias ningún tipo de autorización administrativa ambiental o la realización de un estudio de impacto ambiental previo, independientemente de que dicha actividad sea potencialmente peligrosa en un punto fronterizo que los une. A su vez, el tratado autoriza el aumento de emisiones de gases de efecto invernadero sin limitaciones y establece que no le son aplicables los principios de prevención, precaución y cooperación en materia medioambiental.

69 Para mayor información: https://www.urgenda.nl/en/themas/climate-case/climate-case-explained/

70 Artículo 28 del Acuerdo de París establece: "1. Cualquier de las Partes podrá denunciar el presente Acuerdo mediante notificación por escrito al Depositario en cualquier momento después de que hayan transcurrido tres años a partir de la fecha de entrada en vigor del Acuerdo para esa Parte. 2. La denuncia surtirá efecto al cabo de un año contado desde la fecha en que el Depositario haya recibido la notificación correspondiente o, posteriormente, en la fecha que se indique en la notificación. 3. Se considerará que la Parte que denuncia la Convención denuncia asimismo el presente Acuerdo." 
Tiempo después, en el Estado "Alfa" cambia la administración del gobierno. El nuevo gobierno está preocupado porque en "Beta" se está por comenzar la construcción de varios emprendimientos industriales, a saber: una planta industrial de gran porte, que prevé la quema de combustibles fósiles (derivados del petróleo y el carbón), la fabricación de elementos químicos que prevén la evacuación de efluentes en un río internacional y la posibilidad de instalar una central nuclear en la frontera, muy cerca de los principales centros poblados de "Alfa". Ante esta situación, "Alfa" solicita información a "Beta", quien se niega a remitir cualquier tipo de información fundándose en el tratado oportunamente firmado.

Ante la falta de cooperación, "Alfa" acude a la Corte Internacional de Justicia, órgano que tiene jurisdicción compulsoria de acuerdo al tratado firmado. La CIJ, ¿aplicará sin más el tratado, basándose en el principio de pacta sunt servanda y el respeto de las obligaciones de buena fe?

Esta interpretación parecería difícil de sostener en el estado actual de avance sobre las normas internacionales de protección del medio ambiente. Pero, si dichas normas fueran simplemente -ius dispositivum- la realidad es que no podrían hacerse valer por encima de un tratado válido. Como hemos visto más arriba, un tratado puede válidamente modificar la costumbre. Será necesario entonces acudir, a realizar una interpretación que establezca que las normas internacionales que protegen el medio ambiente, tienen una jerarquía superior, son imperativas y producirían la nulidad absoluta del tratado firmado entre "Alfa" y "Beta".

Quizás la CIJ tome la postura de establecer, para darle jerarquía a dichas normas, y en definitiva desaplicar el tratado bilateral, la interpretación de que las obligaciones internacionales de protección del medio ambiente son "obligaciones erga omnes". A nuestro modesto entender, ésta ha sido la técnica elegida por la CIJ para establecer una jerarquía normativa de ciertas obligaciones por sobre otras, sin ingresar a nombrar ciertas normas como imperativas de derecho internacional general -ius cogens-, pero indirectamente aplicándoles un efecto similar (la aplicación jerárquica de unas obligaciones por sobre otras). Desde un punto de vista meramente práctico, lo realmente importante es saber qué norma se aplicará a un asunto concreto, más allá de que la norma que sea desaplicada, eventualmente se declare como nula o inexistente.

¿Cuándo nace una norma ius cogens? Esta interrogante no es claramente abordada por la Comisión de Derecho Internacional de las Naciones Unidas. Los medios probatorios $¿$ Tienen un efecto constitutivo de normas ius cogens o tienen un efecto simplemente declarativo? La respuesta a esta interrogante nos parece por demás importante en el estado actual del derecho internacional contemporáneo. En la práctica, las normas que, indiscutiblemente, han alcanzado la jerarquía de ius cogens, no han tenido una declaración por la "comunidad internacional de estados en su conjunto" sobre tal carácter.

Al contrario, la práctica ha sido que, quizás primero la doctrina especializada se ha pronunciado a favor de que ciertas normas tienen carácter de ius cogens $\mathrm{y}$, posteriormente, la CIJ u otras cortes internacionales o nacionales, en respuesta a una solicitud en concreto, han fallado utilizando una norma imperativa como fundamento jurídico de 
sus decisiones. En algunos casos, dichas cortes han inaplicando tratados multilaterales o bilaterales vigentes. En general, la prueba ofrecida por la CIJ para declarar una norma como ius cogens no se ha basado en declaraciones de los estados, o en tratados multilaterales (no conocemos ningún tratado bilateral o multilateral que en su texto establezca que sus normas son ius cogens - además de que, dicha declaración en un tratado, por sí sola, no sería suficiente para determinar el carácter imperativo de una norma internacional) sino más bien en opiniones jurídicas doctrinarias, que cómo hemos visto, son ampliamente válidas para establecer tal carácter.

\section{CONCLUSIONES.}

En Derecho Internacional existe una bifurcación normativa. Por un lado podemos mencionar el "ius dispositivum", normas en las cuales los sujetos de derecho internacional tienen la más amplia potestad normativa, y por el otro, el "ius cogens", normas imperativas de derecho internacional general.

Las características distintivas de las normas ius cogens son: imperatividad, generalidad, aceptación y reconocimiento universal, dinamismo y mutabilidad.

Los sujetos de derecho internacional se han mostrado reacios a expresarse con firmeza para catalogar a una norma de derecho internacional general como ius cogens.

Los criterios acumulativos para la determinación de las normas ius cogens están definidos en el artículo 53 de Convención de Viena sobre Derecho de los Tratados: "debe ser una norma de derecho internacional general", la cual debe ser aceptada y reconocida como una norma que no admite acuerdo en contrario.

Los principios generales de derecho, al igual que las normas de derecho internacional consuetudinario, son de aplicación general.

Las disposiciones de los tratados no constituyen, en sí, normas de derecho internacional general capaces de ser fuente de normas de ius cogens, pueden reflejar normas de derecho internacional general que pueden alcanzar el rango de ius cogens.

Algunas consecuencias de considerar una norma como "imperativa de derecho internacional general" son: la nulidad de los tratados cuyas normas contravienen el ius cogens; el deber de no reconocer como lícita una situación creada por una violación de una norma imperativa de derecho internacional general y una obligación de abstenerse a prestar ayuda o asistencia para mantener una situación creada por una violación a una norma ius cogens;

Las normas imperativas de derecho internacional general (ius cogens) establecen obligaciones erga omnes cuyo incumplimiento concierne a todos los Estados.

Es posible que un tratado derogue una norma consuetudinaria entre las partes y, es también posible que una norma consuetudinaria derogue un tratado. 
El "proyecto de conclusión 8" adoptado por la Comisión de Derecho Internacional el 24 de mayo de 2019, establece mecanismos probatorios de aceptación y reconocimiento del carácter imperativo de una norma de derecho internacional general (ius cogens).

En el marco de la presente investigación, se han recabado los siguientes medios probatorios que establecen que las normas de protección del medio ambiente son normas imperativas de derecho internacional general - ius cogens: una declaración pública hecha en nombre de un Estado (Alemania); una publicación oficial (Alemania); dos decisiones de cortes y tribunales nacionales (Alemania y Colombia); innumerables disposiciones en tratados multilaterales que declaran derecho consuetudinario.

Puede concluirse que, en el marco de la presente investigación, la cantidad y calidad de los medios principales de comprobación es bajo.

El "proyecto de conclusión 9" adoptado por la Comisión de Derecho Internacional el 24 de mayo de 2019, establece "medios auxiliares" de determinación del carácter imperativo de las normas de derecho internacional general (ius cogens).

En el marco de la presente investigación, se han recabado los siguientes medios auxiliares de comprobación a los efectos de establecer que las normas de protección del medio ambiente son normas imperativas de derecho internacional general - ius cogens: una decisión de "cortes y tribunales internacionales" que califica como obligación erga omnes a la protección del medio ambiente (Corte IDH); una declaración de órganos de expertos establecidos por Estados o por organismos internacionales (Comisión de Derecho Internacional); diez opiniones de doctrina de los publicistas de mayor competencia de las distintas naciones (principalmente en el ámbito latinoamericano).

Puede concluirse que, en el marco de la presente investigación, la cantidad y calidad de los medios auxiliares de comprobación son aceptables.

En nuestra opinión, el sustento doctrinario actualmente es suficiente para que, en un futuro, y ante una solicitud en concreto en tal sentido, la CIJ se pronuncie declarando las normas que protegen el medio ambiente como normas ius cogens. Respetando el tracto lógico que ha primado hasta ahora en la declaración de normas ius cogens, una vez que la CIJ la invoque, más Estados y Organizaciones Internacionales comenzarán a replicar dicha invocación.

\section{BIBLIOGRAFÍA}

\section{Informes y documentos:}

Documento A/CN.4/L936 Comisión de Derecho Internacional 71er período de sesiones. Ginebra, 29 de abril a 7 de junio y 8 de julio a 9 de agosto de 2019. Fecha 24 de mayo de 2019. Texto del proyecto de conclusiones por el Comité de Redacción en primera lectura.

Documento A/CN.4/727 Cuarto informe sobre las normas imperativas de derecho internacional general (ius cogens) presentado por Dire Tladi, Relator Especial. 
Documento A/CN.4/706 Segundo informe sobre ius cogens presentado por Dire Tladi, Relator Especial. 16 de marzo de 2017.

Documento A/CN4.714 Tercer informe sobre las normas imperativas de derecho internacional general (ius cogens) presentado por Dire Tladi, Relator Especial. 12 de febrero de 2018.

Opinión consultiva OC 23-17, sobre Medio Ambiente y Derechos Humanos de la Corte Interamericana de Derecho Humanos.

Opinión consultiva de la Corte Internacional de Justicia sobre la legalidad de la amenaza o el empleo de armas nucleares.

Sentencia del caso de las plantas de celulosa sobre el Río Uruguay (Argentina Vs. Uruguay). 20 de abril de 2010.

Documento A/73/419 Lagunas en el derecho internacional del medio ambiente y los instrumentos relacionados con el medio ambiente: hacia un pacto mundial por el medio ambiente. Secretario General de las Naciones Unidas.

Centro de Estudios en Derechos Humanos de la Universidad Autónoma de Yucatán, en el escrito de observaciones sobre la solicitud de Opinión Consultiva relativa a la interpretación de los artículos 1.1, 4.1 y 5.1 del Pacto de San José. Enero 2017 CARBALLO, CRUZ, GONZÁLEZ y RUBIO.

Programa de las Naciones Unidas para el Medio Ambiente en cooperación con el Sabin Center for Climate Change Law de la Columbia Law School. "El estado del litigio en materia de Cambio Climático - una revisión global"

\section{Artículos y libros:}

AKEHURST, Michael “A Modern Introduction to International Law”. Séptima edición.

ROHR, Aldana "La responsabilidad internacional del Estado por violación al jus cogens" 1a ed . - Avellaneda : SGN Editora, 2015.

Jiménez de Aréchaga, Arbuet-Vignali y Puceiro Ripoll. “Derecho Internacional Público" Tomo 1. Fundación de Cultura Universitaria. Primera edición, noviembre 2005.

Lecciones de Derecho Internacional Público, González Napolitano, Silvina S. (coord.), Errepar, Buenos Aires, 2015.

GODIO, Leopoldo. Los principios generales de derecho como fuente del derecho internacional público" Revista de derecho de la Universidad de Montevideo, número 30 - año 2016.

BLENGIO VALDÉS, Mariana

Derecho humano a un medio ambiente sano 
En: Revista de Derecho de la Universidad de Montevideo, año 2, no. 4 (2003), Disponible en: http:/ / revistaderecho.um.edu.uy /

Fecha de consulta: 07/10/2019

MANTERO SAN VICENTE, Osvaldo. Derecho Ambiental. Página 19. $1^{\text {a }}$ edición, setiembre 1995.

BRILMAN, Marina C.

Permanencia y cambio de la normatividad en el derecho internacional En: Urueña, René. Derecho internacional: poder y límites del derecho en la sociedad global. Bogotá: Universidad de los Andes, 2015.

Acceso a biblioteca: vLex

Fecha de consulta: 07/10/2019

CANÇADO TRINDADE “La Ampliación del Contenido Material del JUS COGENS” página 6. Publicado en la recopilación del XXXIV Curso de Derecho Internacional de la Organización de Estados Americanos. Disponible en: http://www.oas.org/es/sla/ ddi/docs/publicaciones_digital_xxxiv_curso_derecho_internacional_2007_antonio_augusto_cancado_trindade.pdf

DIEZ DE VELASCO, Manuel. Instituciones de Derecho Internacional Público. Undécima edición.

ECHAIDE, Javier

Demandas en el CIADI y el derecho humano al agua: ¿tratados de inversiones vs. derechos humanos?

En: Revista Colombiana de Derecho internacional, no. 31 (2017)

Acceso en biblioteca: vLex

LUCERO PANTOJA, Jairo Enrique

Funcion de utilidad. Entre el ambiente y el sostenimiento de la economía

En: Medio Ambiente \& Derecho. Revista electrónica de derecho ambiental, no. 32

Acceso en biblioteca: vLex

DRNAS de CLÉMENT, Zlata “El daño deliberado y substancial al medio ambiente, como objetivo, medio o método de guerra constituye violación de norma imperativa de derecho internacional general". Disponible en: https://www.icrc.org/es/doc/assets/ files/other/10_zlata.pdf

PEZZANO, Luciano

Responsabilidad internacional ambental por conflicto armado

En: RECORDIP, vol. 1, no. 2 (2015)

Disponible: https://revistas.unc.edu.ar/index.php/recordip/article/view/13290

Recomendación no. 4: La efectividad del derecho internacional del medio ambiente En: Revista Catalana de Dret Ambientalvol. 2, no. 2 (2011) 
SERVI, aldo

Derecho ambiental: responsabilidad ambiental internacional

En: Jurisprudencia Argentina. La Ley Online, Argentina.

Cita Online: 0003/008054

SERVI, Aldo

El derecho internacional del medio ambiente.

En: Revista de Relaciones Internacionales, no. 14

Disponible en: http:/ /www.iri.edu.ar/revistas/revista_dvd/revistas/R14/R14-ESER.html

TELLEZ-NUÑEZ, Adrés

Lo justo ambiental en el contexto de normas imperativas de derecho internacional público.

En: Revista de la Facultad de derecho y Ciencias Políticas (UPB), v. 47, no. 127 (2017).

Disponible en: http:/ /www.scielo.org.co/pdf/rfdcp/v47n127/0120-3886-rfd-

cp-47-127-335.pdf

VALENCIA RESTREPO, Hernán

La definición de los principios en el Derecho internacional contemporáneo.

En: Revista de la Facultad de Derecho y Ciencias Politicas, vol. 37, no. 106 (2007) p. 69-124

Disponible en: https:/ / revistas.upb.edu.co/index.php/derecho/article/

view $/ 5520 / 5113$

VIÑUALES, Jorge E.

La protección del medio ambiental y su jerarquía normativa en derecho internacional En: International Law: Revista Colombiana De Derecho Internacional, 6(13) (2008)

Disponible en:

https://revistas.javeriana.edu.co/index.php/internationallaw/article/view/13902

GOROSITO ZULUAGA, Ricardo Los principios en el Derecho Ambiental En: Revista de Derecho (UCU), no. 16 (2017), p. 101-136

Disponible en: http:/ /www.scielo.edu.uy/pdf/rd/n16/2393-6193-rd-16-00101.pdf 